\title{
A Position Sensorless Control of Switched Reluctance Motors Based on Phase Inductance Slope
}

\author{
Jun Cai ${ }^{\dagger}$ and Zhiquan Deng* \\ ${ }^{\dagger *}$ College of Automation engineering, Nanjing University of Aeronautics and Astronautics, Nanjing, China
}

\begin{abstract}
A new sensorless position estimation method for switched reluctance motor (SRM) drives is presented in this paper. This method uses the change of the slope of the phase inductance to detect the aligned position. Since the aligned positions for successive electrical cycle of each phase are apart by a fixed mechanical angle $45^{\circ}$ in the case of $12 / 8 \mathrm{SRM}$, the speed of the machine can be calculated to estimate the rotor position. Since no prior knowledge of motor parameters is required, the method is easy for implementation without adding any additional hardware or memory. In order to verify the validity of this technique, effects such as changes in the advanced angle and phase lacking faults are examined. In addition, an inductance threshold based sensorless starting scheme is also proposed. Experimental results demonstrate the validity of the proposed method.
\end{abstract}

Key words: Fault-tolerant, Phase inductance slope, Position estimation, Sensorless, Switched Reluctance Motor

\section{INTRODUCTION}

Switched reluctance motor (SRM) drive is considered as an attractive candidate for variable speed motor drives due to its own advantages. These drives are suitable for applications such as electric vehicles, aircraft starter/generator systems, mining drives, robotics and etc [1], [2]. However, the use of mechanical position sensors add to the cost and dimension and deteriorate the reliability of the SRM drives. Therefore, it is quite necessary to develop a reliable sensorless method.

Widespread researches in the area of the sensorless rotor position estimation of SRMs have been done in recent years. The main idea of the traditional sensorless techniques stems from the fact that the mechanical time constant of SRM drives is much larger than its electrical time constant. Therefore, one can recover the encoded position information that is stored in the form of electromagnetic characteristics such as flux linkage, inductance, back-emf, and so on by solving the voltage equation in an active or idle phase. From the aspects of rotor position decoding methods, the following methods such as look-up table [3], mathematical model [4], [5], observer [6], [7], and intelligent approximation algorithm

\footnotetext{
Manuscript received Oct. 8, 2011; revised Jan. 1, 2013

Recommended for publication by Associate Editor Jung-Ik Ha.

${ }^{\dagger}$ Corresponding Author: qinghuadianji@163.com

Tel: +86-159-5192-4198, Nanjing Univ. of Aeronautics and Astronautics

${ }^{*}$ College of Automation engineering, Nanjing University of Aeronautics and Astronautics, China
}

[8]-[11] based methods and such are included. This implies that to implement these estimation methods, some prior knowledge of the SRM should be known. In [12], the current gradient based sensorless method (CGS) is proposed. This method uses the change of the derivative of the phase current to detect the position where a rotor pole and stator pole start to overlap (giving one position update per energy conversion) which requires no prior knowledge and is easily applicable to most SRM topologies in a wide power and speed range. However, some additional analog detecting circuits are required for implementation of the methods. In [13], the CGS method is utilized in an ultra high speed SRM system. As analyzed in this paper, the stability of the CGS method is sensitive to the effects such as motor magnetic saturation, speed variations, and advance angles. Thus, before implementation, many simulation and experimental works need to be done carefully to determine the suitable boundaries of these parameters, which make this method relatively difficult to implement. In [14], a sensorless method based on gradient of phase inductance is described. As discussed in this paper, the aligned position is defined as the commutation position, which is detected according to the polarity change of the gradient of phase inductance. However, this method is not suitable for high speed operation due to the large negative torque generated.

Ideally, it is desirable to develop a sensorless scheme, which neither requires additional hardware nor occupy too much memory while maintaining a reliable operation over a 
wide speed range. In this paper, a new sensorless position estimation method for SRM based on phase inductance slope zero-crossing detection (PISZ) is presented. The systematic analysis of the principle, the experimental implementation, and the performance evaluation are given in the following sections.

This paper is organized as follows: Section II presents the principle of the proposed position estimation method; Section III briefly discusses the experimental results; Section IV concludes this paper.

\section{PRINCIPLE ANALYSIS OF THE PROPOSED POSITION ESTIMATION METHOD}

\section{A. Basic Principle of the PISZ Method}

The typical characteristics of phase inductance and inductance slope are shown in Fig. 1(a) and (b) respectively. The stator phase inductance and its slope vary periodically with the rotor position and also the instantaneous phase current due to magnetic saturation. As shown in Fig. 1(b), the slope of the phase inductance becomes zero at the aligned and unaligned positions. Ideally, by detecting the zero-crossing points of the inductance slope, the aligned position or unaligned position in each phase can be estimated. The position estimation scheme introduced here is based on detection of the aligned position in each phase. As shown in Fig. 2, the aligned positions for successive electrical cycle of each phase are apart by a fixed mechanical angle of $45^{\circ}$ in a $12 / 8$ SRM; thus, the electrical speed of the machine can be calculated to estimated the rotor position.

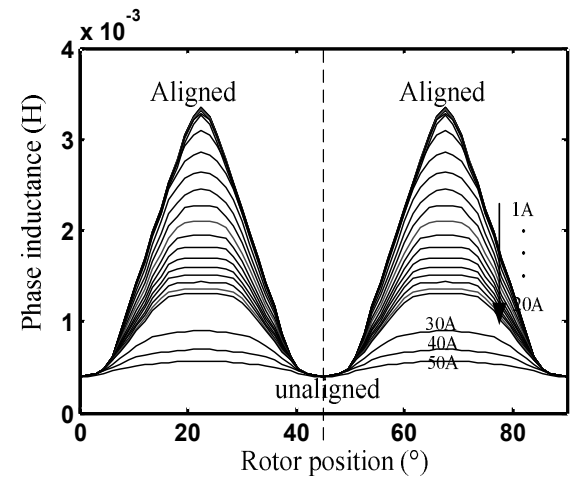

(a)

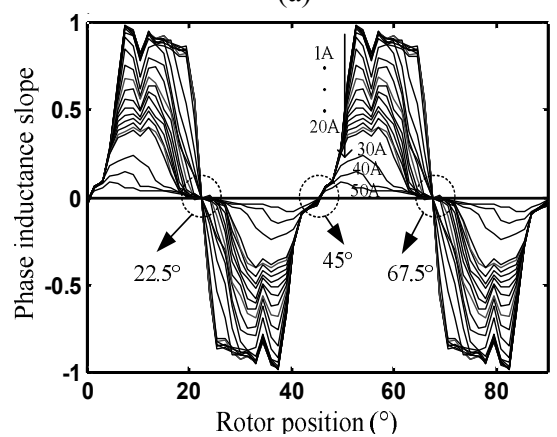

(b)

Fig. 1. (a) Phase inductance characteristics; (b) inductance slopes.

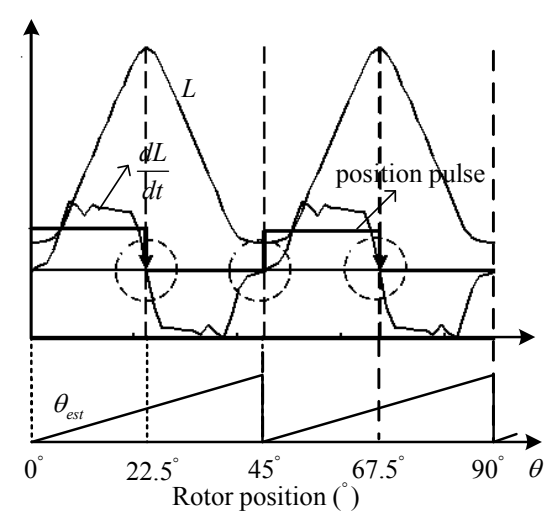

Fig. 2. Basic principle diagram of the PISZ method.

\section{B. Phase Inductance Estimation}

In each phase of the SRM, the flux linkage can be estimated by (1) in the absence of mutual coupling.

$$
\psi(t)=\int_{0}^{t}[v(t)-i(t) r(t)] d t
$$

where $t, v(\mathrm{t}), r(\mathrm{t}), i(\mathrm{t})$, and $\psi$ are the time, applied voltage, phase resistance, phase current, and the flux linkage respectively.

In DSP controller, the flux linkage integration is implemented in the discrete time using the Euler method.

$$
\psi(k+1)=\psi(k)+(v(k)-r i(k)) \times T_{s}
$$

where $T_{s}$ is the sampling time, $\psi(k)$ and $\psi(\mathrm{k}+1)$ are the flux linkages at $k^{\text {th }}$ and $(k+1)^{\text {th }}$ sampling instants and $i(\mathrm{k})$ and $v(\mathrm{k})$ are the phase current and phase voltage at $k^{\text {th }}$ sampling instant, respectively.

The flux linkage and phase inductance is related by the following equation

$$
L(i, \theta)=\frac{\psi(\theta, i)}{i}
$$

where $L$ is the phase inductance and $\theta$ is the rotor position. It is clear that the phase inductance can be calculated once the phase voltage and current are measured. However, in the idle phases, the phase current will decay to zero. In this case, if no additional signals are injected, estimating the phase inductance will be cumbersome. Generally, when the phase current is zero, the value of phase inductance is set to zero in software. The typical waveform of the estimated phase inductance is shown in Figs. 3 and 4.

If sample time is small enough, the inductance slope can be represented as the inductance gradient form.

$$
\frac{\Delta L}{\Delta T}=\frac{L(k+1)-L(k)}{T_{s}}
$$

where $L(k)$ and $L(\mathrm{k}+1)$ are the inductance at $k^{\text {th }}$ and $(k+1)^{\text {th }}$ sampling instants, and $T_{s}$ is the sampling time.

\section{Analysis of the Problems in PISZ Method Caused by} Phase Inductance Estimation 


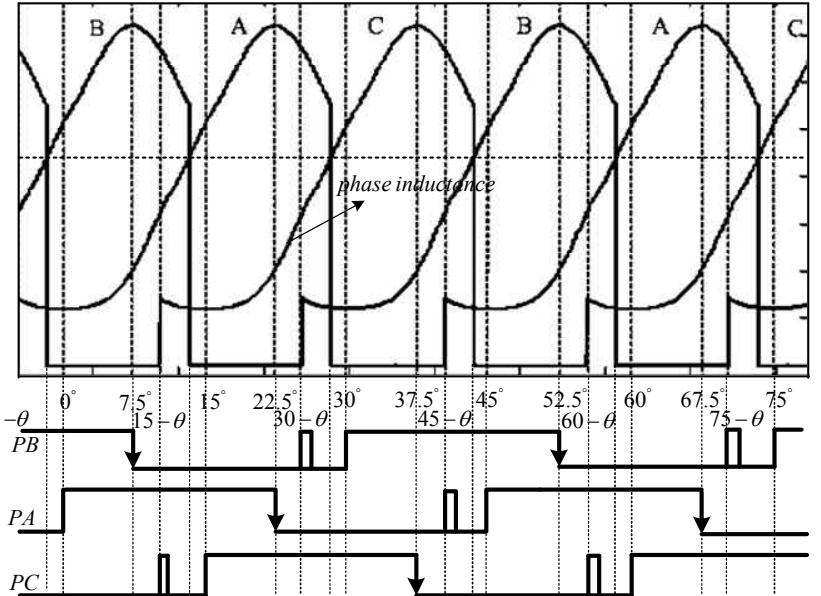

Fig. 3. Principle diagram of the PISZ method with $\theta_{\text {on }}<0^{\circ}$.

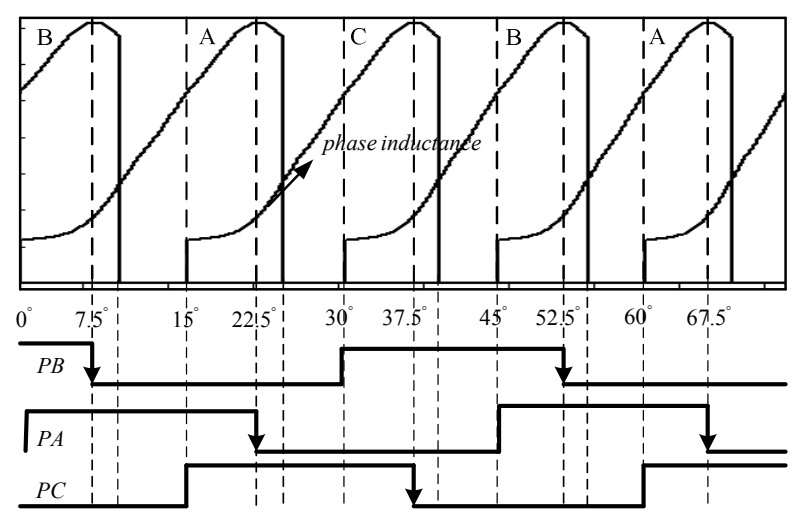

Fig. 4. Principle diagram of the PISZ method with $\theta_{\mathrm{on}}>=0^{\circ}$.

TABLE I

NeW SubRegionAl LOGICS OF THE IPISZ MeTHOD

\begin{tabular}{|c|c|c|}
\hline $\begin{array}{c}\text { Amplitudes order } \\
\text { of phase } \\
\text { inductance }\end{array}$ & Position Region & $\begin{array}{c}\text { Norm estimation } \\
\text { phase }\end{array}$ \\
\hline$L a>L c \& L a>L b$ & Region 1 & $\mathrm{~A}$ \\
\hline$L c>L a \& L c>L b$ & Region 2 & $\mathrm{C}$ \\
\hline$L b>L a \& L b>L c$ & Region 3 & $\mathrm{~B}$ \\
\hline return & $\ldots$ & $\ldots$ \\
\hline
\end{tabular}

As discussed in Section II-A, it is difficult to estimate the full cycle phase inductance in real-time control. Generally, the phase inductance is set to zero when the phase current decays to zero. This method simplifies the inductance estimation process, but leads to some problems in position estimation. When the phase is turned-on, the estimated phase inductance will change from zero to the real value so that the calculated inductance slope will have a positive step. This step value will deteriorate the estimation performance when the turn-on angle is advanced, because in this case the polarity of the calculated inductance slope will change twice
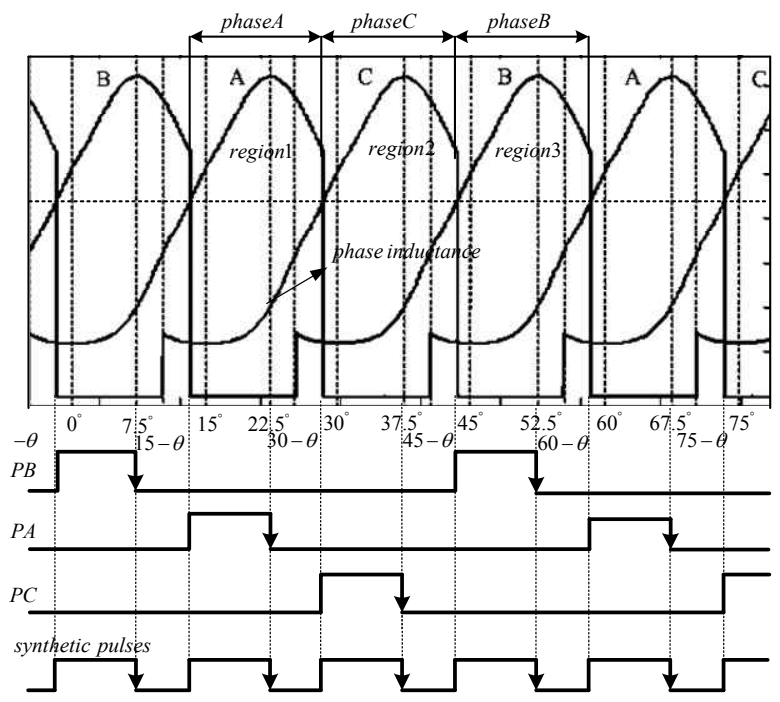

Fig. 5. Principle diagram of the IPISZ method.

in each electrical cycle. The estimation results when the turn-on angle is advanced and not advanced are shown in Figs. 3 and 4, respectively. As shown in Fig. 3, two sensorless index pulses appear per electrical cycle, where it is clear that the first one is erroneous. In contrast in Fig. 4, there are no erroneous index pulses and the rotor position can be estimated accurately.

Obviously, the erroneous pulses complicate the position estimation process severely. To solve this problem without adding any additional hardware, an improved PISZ method (IPISZ) is proposed. As described in Table I, the phase with the largest inductance is chosen as the estimation phase. Accordingly, the PISZ method can be utilized in the estimation phase. In this way, there is strictly only one index pulse in the corresponding region. The principle diagram of this method is shown in Fig. 5. For a 12/8 structure SRM prototype, every two index pulse falling edges per phase has a phase difference $\triangle \theta=45^{\circ}$; therefore, by recording the time difference between them the rotor position and speed can be estimated.

$$
\omega=\frac{\Delta \theta}{\Delta t}
$$

where $\triangle \theta$ and $\Delta t$ are the phase difference and time difference of two pulse falling edges, $\omega$ is the rotor speed.

$$
\theta(k+1)=\theta(k)+\omega \times \Delta T
$$

where $\theta(k+1)$ and $\theta(k)$ are the sampled rotor position in the neighboring sample cycle, and $\triangle T$ is the interrupt cycle of DSP timer.

\section{Analysis of the Fault-Tolerant Performance of the PISZ} and IPISZ Sensorless Methods

As is known, good fault-tolerant capability is one of the most important merits of SRM drives. Though numerous sensorless control methods have been reported in past literatures, the fault-tolerant capability of them is never 
TABLE II

The COMPARISON OF THE PISZ AND IPISZ METHOD UNDER DIFFERENT OPERATION CONDITIONS

\begin{tabular}{|c|c|c|c|}
\hline $\begin{array}{c}\text { Operation } \\
\text { modes }\end{array}$ & $\begin{array}{c}\text { PISZ } \\
\left(\theta_{\text {on }} \geqslant 0\right)\end{array}$ & $\begin{array}{c}\text { PISZ } \\
\left(\theta_{\text {on }}<0\right)\end{array}$ & IPISZ \\
\hline Normal & Good & Bad & Best \\
\hline $\begin{array}{c}\text { One phase } \\
\text { lacking }\end{array}$ & OK & NO & NO \\
\hline $\begin{array}{c}\text { Two phases } \\
\text { lacking }\end{array}$ & OK & NO & NO \\
\hline
\end{tabular}

discussed. In this work, the fault-tolerant capability of the PISZ and IPISZ methods under phase lacking faults are investigated.

From the discussions in the above section, some conclusions can be drawn. 1) The PISZ method is only suitable for working in the mode without turn-on advance angle. In this operation mode, the rotor position can be estimated from any individual phases. Therefore, this method possesses good fault-tolerant capabilities, which can maintain sensorless operation even under phase lacking faults conditions. However, the speed adjusting performance will deteriorate with the increase of rotor speed. 2) The IPISZ method possesses better speed adjusting performance than the PISZ method under normal operation mode, because the turn-on angle is adjustable. In IPISZ senorless operation mode, the conventional control strategies of SRM drives can be utilized easily without corrections. However, in IPISZ sensorless mode, the three-phase inductance signals need to be known at any instants for the inductance subregion process. Thus, this method can not be used under fault conditions.

The performance comparison of these two methods under normal operation and fault operation are given in Table II.

\section{E. Analysis of the Influence Factors on Rotor Position Estimation}

1) Effects of neglecting the mutual couplings: Considering the mutual coupling between SRM phases, the phase voltage equation can be represented as

$$
\begin{aligned}
& U_{a} \\
& =R i_{a}+\frac{d\left[L_{a}\left(\theta, i_{a}\right) i_{a}\right]}{d t}+\frac{d\left[M_{a b}\left(\theta, i_{b}\right) i_{b}\right]}{d t}+\frac{d\left[M_{a c}\left(\theta, i_{c}\right) i_{c}\right]}{d t}
\end{aligned}
$$

Where, Mab and Mac are the mutual inductance between adjacent phases. It is clear that the adding of the mutual inductance terms makes the voltage equation more accurate. However, the equation becomes more complicated and not suitable for implementation.

As reported in [15], the flux-linkage error caused by the mutual coupling is around $7 \%$, which is relative small. Therefore, the mutual coupling is usually neglected for flux linkage estimation and sensorless control [3]-[14]. In this paper, the mutual coupling is also neglected. There is no doubt that the neglecting of mutual coupling may influence the estimation accuracy of the phase inductance and lead to some calculation errors in amplitudes of the inductance slopes, but the zero-crossing points of the inductance slopes will not be affected. Therefore, the performance of the proposed sensorless scheme will not be influenced by the mutual coupling reasons.

2) Effects of the asymmetry of three-phase inductance: As is known, ideally each phase inductance of the SRM prototype is symmetric. However, sometimes for the mechanical reasons or measurement error, the phase inductance are always not strictly symmetrical. From this perspective, it is necessary to study the estimation performance of the sensorless method under the circumstances of asymmetric phase inductance.

At first, in different rotor positions, we use (8) to represent the degree of asymmetry of phase inductance

$$
\lim _{\mathrm{k} \rightarrow 1} L^{\prime}=\lim _{\mathrm{k} \rightarrow 1} \mathrm{k} L=L \quad(\mathrm{k} \rightarrow 1)
$$

Where, $k$ is the asymmetric coefficient, $\mathrm{k} \in(0,1) \cup(1,+\infty)$, and close to 1 .

As shown in Fig. 4, it is clear that the position estimation is independent of the amplitude of phase inductance. Therefore, the PISZ method is not affected by the asymmetry of phase inductance, even if the asymmetry is severe. Similarly, when $k$ is close to 1 , the IPISZ method will not be affected.

3) Effects of magnetic saturation: Due to the double salient structure, the magnetic characteristic of SRM appears highly nonlinear. For instance, the phase inductance is the function of both rotor position and phase current. Fig. 1(a) shows the inductance characteristics. In APC control mode, the phase current will decrease when the rotor and stator poles begin to overlap. In addition, the SRM should be controlled by commutation before the aligned position so that the freewheeling current can be reduced to a small value around the aligned position and then the SRM can be accelerated by relatively large effective torque. Due to these reasons, the magnetic saturation will be weakened gradually from the begin-overlap position to the aligned position. On the other hand, the effects of magnetic saturation around the unaligned positions are quite small and can be neglected. Therefore, the estimated phase inductance will increase from the unaligned position to the aligned position monotonically even under magnetic saturations. Thus, the proposed sensorless method will not be affected by magnetic saturation reasons.

4) Effects of the rotor speed: The problem with this method is the inaccurate estimation of flux linkage at low speed. At high speed operation, the phase voltage keeps its positive polarity until the phase is tuned-off. In (1), the $v(\mathrm{t})$ is a dominating term in $[v(\mathrm{t})-r(\mathrm{t}) i(\mathrm{t})]$ and integration of 
$[v(\mathrm{t})-r(\mathrm{t}) i(\mathrm{t})]$ in a relative short period will not lead to huge error in flux estimation. At low speed, however, the phase voltage changes its polarity from one hysteresis cycle to the next hysteresis cycle. When $[v(\mathrm{t})-r(\mathrm{t}) i(\mathrm{t})]$ is integrated in a relative long period, the phase voltage term cancels itself due to the excursions while the $r(\mathrm{t}) i(\mathrm{t})$ term keeps its polarity during the integration period and becomes significant after long time of integration. The error in the variation of $r(\mathrm{t})$ and the measurement of $i(\mathrm{t})$ may lead to huge error in flux estimation in this case. Therefore, this sensorless control method is more suitable for high speed operation of the SRM. In order to start the SRM from standstill and maintain operation at low speed range, some pulse injection based methods $[4][5][7]$ can be utilized. Yet in this paper, the implementation of these methods is not discussed.

5) Effects of turn-off angle: According to the principle of the PISZ and IPISZ methods, in order to estimate the rotor position, the phase inductance at the aligned position must be known. Thus, it is essential to select a suitable turn-off angle to ensure the freewheeling current decays to zero after the aligned position. Through simulation, the turn-off angle $\theta_{\text {off }}=17^{\circ}$ is selected in the experimental system.

\section{6) Effects due to errors in terminal measurements of current} and voltages: For obtaining the phase current and voltage data, the corresponding hall sensors are used. The current sensors have an accuracy of $0.2 \%$ and the voltage sensors have an accuracy of $0.6 \%$. The sensed current and voltage signals are sampled by the A/D converter of the DSP2812 controller and the results are used for phase inductance estimation. The conversion error of the A/D converter can be estimated as

$$
E_{A / D}=2^{-\sigma}
$$

where $\sigma$ is the number of the bits of $\mathrm{A} / \mathrm{D}$ converter. In DSP2812, a 12 bits A/D converter is used for signal sampling. Thus, the error of the A/D conversion is $0.0244 \%$, which is quite small and is not considered in this work.

The current and voltage in SRM drives undergo switching at high frequency. The leakage inductance and finite coupling capacitance can cause noise on measured current and voltage. The noise may lead to some errors in phase inductance calculation. In order to minimize the signal interference and sensing error, the low pass digital filter is designed with the following forms:

$$
\begin{gathered}
I_{F}(n)=(1-\alpha) I_{F}(n-1)+\alpha I_{S}(n) \\
U_{F}(n)=(1-\beta) U_{F}(n-1)+\beta U_{S}(n)
\end{gathered}
$$

$I_{\mathrm{F}}$ and $I_{\mathrm{S}}$ stand for the filtered and sampled current; $U_{\mathrm{F}}$ and $U_{\mathrm{S}}$ stand for the filtered and sampled voltage; $\alpha$ and $\beta$ are the filter coefficients.

7) Effects due to variation of phase resistance: The phase resistance is sensitive to the variation of temperature, which can lead to the integration errors. In our experimental system, the SRM is not working in long-term operation. Thus, the variation of the winding resistance is not significant and is neglected.

\section{F. The Sensorless Starting Scheme}

1) Idle phase inductance estimation: The power converter is the classical three-phase asymmetric half bridge circuits. Without additional hardware, the high frequency diagnostic pulses can be injected into any phases by the power converter. If the switching time interval between turn-on mode and turn-off mode is short enough, it is assumed that the current in these two switching modes are almost constant. Therefore, the voltage drops of the resistance in these two switching modes are approximately equal and the back EMFs in these two modes are also similar. Then, the phase inductance can be derived as

$$
L(\theta)=\frac{2\left(U_{d c}+V_{D}-V_{T}\right)}{\Delta I}
$$

$\Delta I=\left.\frac{d i}{d t}\right|_{o n}-\left.\frac{d i}{d t}\right|_{\text {off }}$ is the current slope difference; $U_{\mathrm{dc}}, V_{\mathrm{T}}$,

$V_{\mathrm{D}}$ are the bus voltage, the conduction voltage drop in power switches, and the conduction voltage drop in diodes, respectively; $L(\theta)$ is the self inductance.

From (12), the unsaturated phase inductance is inversely proportional to the current slope difference, and the phase resistance voltage and the EMF are eliminated indirectly.

2) The principle diagram of the sensorless starting scheme: When the initial phase is excited, because the conducting phase current is high, the magnetic saturation can not be neglected. In this paper, a two inductance thresholds based scheme is proposed. The principle diagram is shown in Fig. 6. As shown in this figure, the inductance threshold $L_{\text {high }}$ is equal to the $\mathrm{C}$ phase inductance at $15^{\circ}$ position, and the threshold $L_{\text {low }}$ is equal to the $\mathrm{C}$ phase inductance when $\mathrm{A}$ phase is turned off.

As is known, when the phase is turned off, the phase current will flow through the freewheeling diodes until it becomes zero. In the freewheeling region, the current is relatively high (if the diagnostic pulses are injected) and the resultant pulses current will extend the freewheeling time and lead to high negative torque. Thus, it is not desirable to inject diagnostic voltage pulses in the wheeling region where the phase current remains relatively high. To avoid this problem, the diagnostic pulses should be injected after the freewheeling current decays to a small level $I_{\mathrm{TH}}$. As shown in Fig. 6, when the freewheeling current is lower than $I_{\mathrm{TH}}$, the phase is injected with high frequency pulses, and the inductance can be estimated from (12). By comparing the estimated inductance with the two inductance thresholds, the B-phase turn-on signal and the A-phase turn-off signal can be 


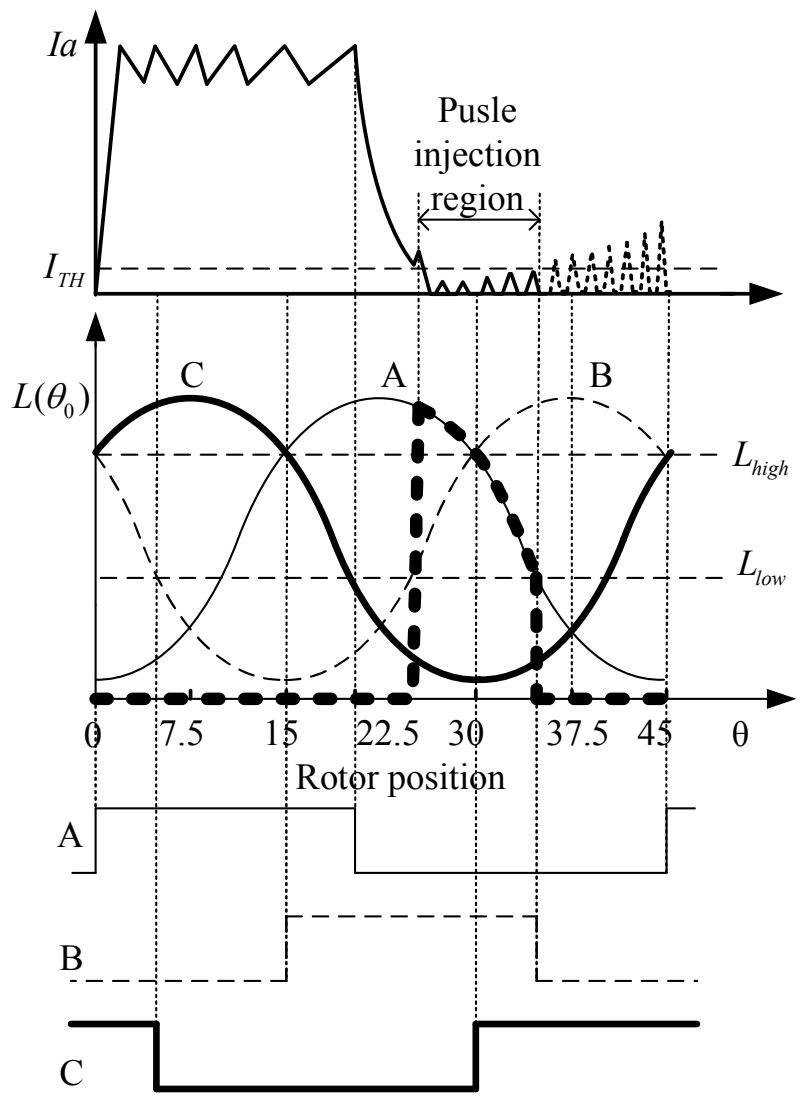

Fig. 6. The principle diagram of the sensorless starting scheme.

estimated respectively. Similarly, the driving signals of each phase can be estimated. The control logics are given in Table III.

As shown in Table III, when the estimated inductance is lower than $L_{\text {low }}$, the estimation phase is changed to the next phase, and the current phase will not inject pulses until it is chosen as the estimation phase in the next electrical cycle. Taking A phase for an example, when the estimated $\mathrm{La}$ is lower than $L_{\text {low }}$, the B-phase is turned off and is chosen as the next estimation phase; meanwhile, the pulse injection signals of A-phase is removed, and the value of the estimated A-phase inductance is set to zero. This method can avoid generating large pulse current around the unaligned position of A-phase, and thus the negative torque can be restricted. Note that, the inductance thresholds $L_{\text {low }}$ and $L_{\text {high }}$ can also be adjusted accordingly: the conduction region can be changed according to the load torque.

\section{3) Sensorless starting at standstill}

To start the SRM from standstill, it is necessary to estimate the initial exciting phase and the initial estimation phase. By injecting high frequency pulses into each phase simultaneously, the inductance of each phase at any initial position can be estimated from (3). Comparing the amplitudes of each phase inductance, the initial exciting phase and the estimation phase can be estimated according to
TABLE III

The Control Logics of THE Starting SCHEME

\begin{tabular}{|c|c|c|c|}
\hline $\begin{array}{c}\text { The } \\
\text { estimation } \\
\text { phase }\end{array}$ & $\begin{array}{c}\text { the } \\
\text { comparison } \\
\text { logics }\end{array}$ & Driving signal & $\begin{array}{c}\text { The next } \\
\text { estimation } \\
\text { phase }\end{array}$ \\
\hline \multirow{2}{*}{$\mathrm{C}$} & $L \mathrm{c} \leqslant L_{\text {high }}$ & B turn-on & $\mathrm{C}$ \\
\cline { 2 - 4 } & $L \mathrm{c} \leqslant L_{\text {low }}$ & A turn-off & A \\
\hline \multirow{2}{*}{$\mathrm{A}$} & $L \mathrm{a} \leqslant L_{\text {high }}$ & C turn-on & $\mathrm{A}$ \\
\cline { 2 - 4 } & $L \mathrm{a} \leqslant L_{\text {low }}$ & B turn-off & $\mathrm{B}$ \\
\hline \multirow{2}{*}{$B$} & $L \mathrm{~b} \leqslant L_{\text {high }}$ & A turn-on & B \\
\cline { 2 - 4 } & $L \mathrm{~b} \leqslant L_{\text {low }}$ & C turn-off & $\mathrm{C}$ \\
\hline
\end{tabular}

TABLE IV

The Control Logics AT STANDSTILL

\begin{tabular}{|c|c|c|c|}
\hline $\begin{array}{c}\text { Comparison } \\
\text { of each } \\
\text { phase } \\
\text { inductance }\end{array}$ & $\begin{array}{c}\text { Position } \\
\text { region }\end{array}$ & $\begin{array}{c}\text { Initial exciting } \\
\text { phase }\end{array}$ & $\begin{array}{c}\text { Initial } \\
\text { estimation } \\
\text { phase }\end{array}$ \\
\hline$L \mathrm{c}>L \mathrm{~b} \geqslant L \mathrm{a}$ & $\left(0,7.5^{\circ}\right]$ & $\mathrm{A}$ and $\mathrm{C}$ & $\mathrm{B}$ \\
\hline$L \mathrm{c}>L \mathrm{a}>L \mathrm{~b}$ & $\left(7.5^{\circ}, 15^{\circ}\right)$ & $\mathrm{A}$ & $\mathrm{C}$ \\
\hline$L \mathrm{a}>L \mathrm{c} \geqslant L \mathrm{~b}$ & $\left(15^{\circ}, 22.5^{\circ}\right]$ & $\mathrm{B}$ and $\mathrm{A}$ & $\mathrm{C}$ \\
\hline$L \mathrm{a}>L \mathrm{~b}>L \mathrm{c}$ & $\left(22.5^{\circ}, 30^{\circ}\right)$ & $\mathrm{B}$ & $\mathrm{A}$ \\
\hline$L \mathrm{~b}>L \mathrm{a} \geqslant L \mathrm{c}$ & $\left(30^{\circ}, 37.5^{\circ}\right]$ & $\mathrm{B}$ and $\mathrm{C}$ & $\mathrm{A}$ \\
\hline$L \mathrm{~b}>L \mathrm{c}>L \mathrm{a}$ & $\left(37.5^{\circ}, 45^{\circ}\right)$ & $\mathrm{C}$ & $\mathrm{B}$ \\
\hline
\end{tabular}

the control logics as given in Table IV. Combining with the control logics as shown in Table III, the SRM can be started from any initial position without hesitation.

\section{EXPERIMENTAL VERIFICATION}

The proposed sensorless methods have been implemented on the experimental SRM driving system. The overall system configuration of the proposed sensorless drive is shown in Fig. 7.

For hardware implementation, a $12 / 8$ SRM is used in the experimental system, the dimension of the SRM is given in Table V; a conventional three-phase asymmetric half-bridge converter controlled by a DSP2812 controller is used for driving the SRM; the current and voltage sensors and their signal modulation circuits are included. For software implementation, the PISZ method, the IPISZ method, the starting scheme and the conventional SRM control algorithms are implemented in DSP controller. Based on the experimental system, related experiments have been done for verification.

The phase current waveform corresponding to the phase inductance and inductance slope with different conduction regions $\left(-3^{\circ}, 17^{\circ}\right),\left(0^{\circ}, 17^{\circ}\right)$ and $\left(3^{\circ}, 17^{\circ}\right)$ are given in Figs. 8(a)-(c), respectively. As shown in Fig. 8(a), an erroneous index pulse is generated at the turned-on instant, which deteriorates the estimation result of PISZ severely. To avoid the defect of this method, the IPISZ method is designed in 


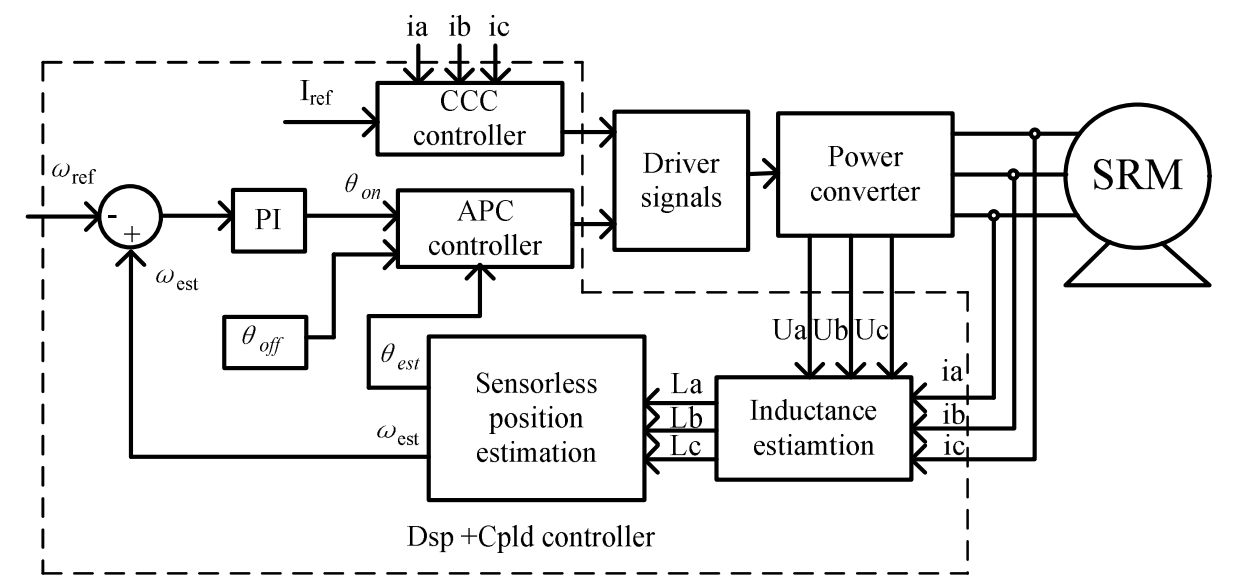

Fig. 7. Block diagram of the sensorless SRM drive.

this work. As shown in Fig. 8(d), the three-phase inductance are divided into three regions according to the amplitudes orders of the estimated phase inductance. The phase with largest inductance is selected as the estimation phase, and then using the PISZ method, the position index pulses of each phase can be estimated accurately.

For further discussion, the experimental results of PISZ and IPISZ methods with different switching angles are compared in Figs. 9(a)-(f). The results show that the IPISZ method is not affected by the advance angle, which possesses good potential for high performance control of SRM drives. As shown in Fig. 10, using the estimated index pulses, the estimated rotor position is in good agreement with the reference position.

TABLE V

The Dimensions of THE MACHINE

\begin{tabular}{|c|c|}
\hline Outside diameter of stator core & $123 \mathrm{~mm}$ \\
\hline Inside diameter of stator pole & $74 \mathrm{~mm}$ \\
\hline Thickness of the stator yoke & $7 \mathrm{~mm}$ \\
\hline Outside diameter of rotor pole & $73.4 \mathrm{~mm}$ \\
\hline Thickness of the rotor yoke & $13 \mathrm{~mm}$ \\
\hline Stator pole-arc coefficient & 0.52 \\
\hline Rotor pole-arc coefficient & 0.383 \\
\hline
\end{tabular}

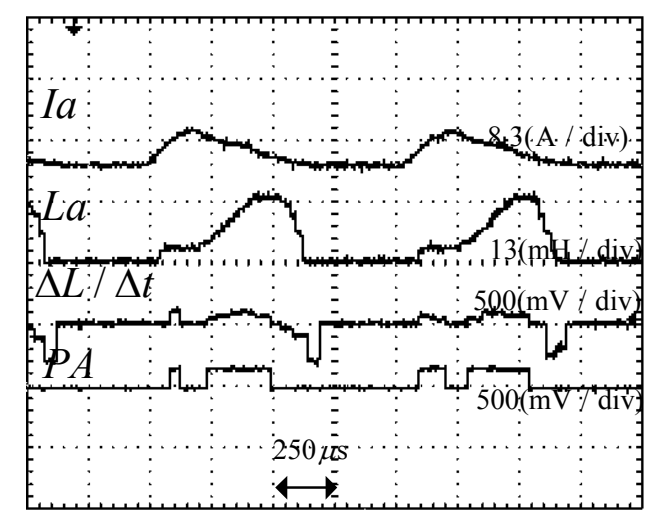

(a) PISZ conduction region $\left(-3^{\circ}, 17^{\circ}\right)$.

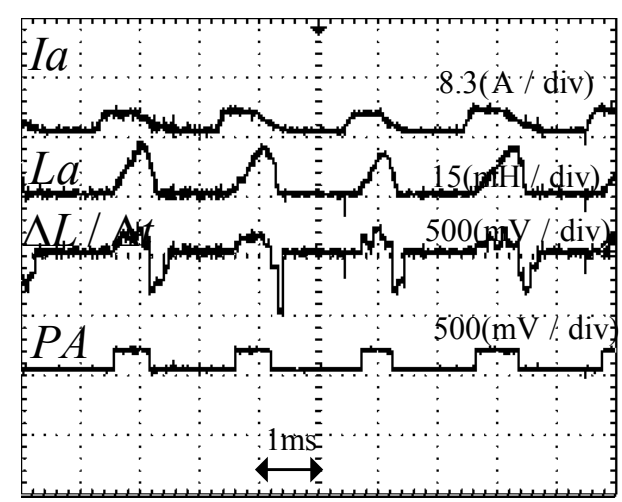

(b) PISZ conduction region $\left(0^{\circ}, 17^{\circ}\right)$.

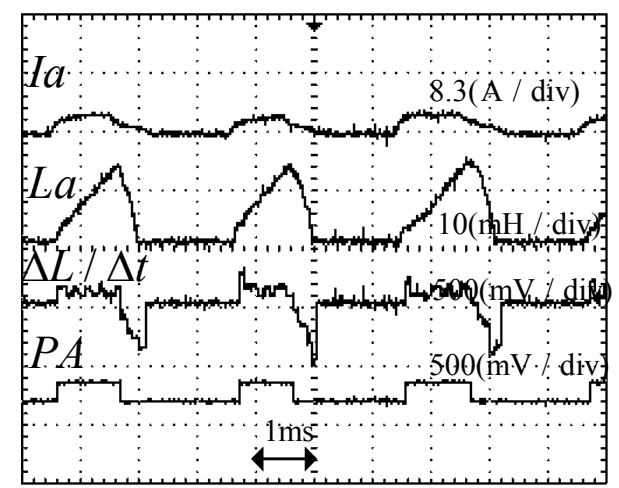

(c) PISZ conduction region $\left(3^{\circ}, 17^{\circ}\right)$.

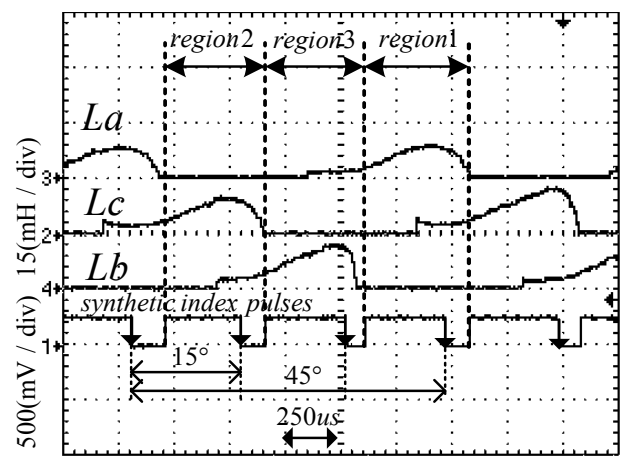

(d) IPISZ with $\theta_{\text {on }}<0^{\circ}$.

Fig. 8. Principe verification of PISZ and IPISZ. 


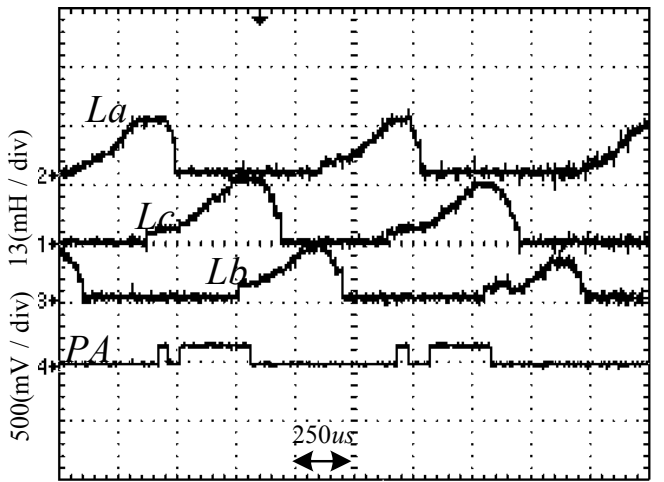

(a) PISZ with $\theta_{\text {on }}=-3^{\circ}$.

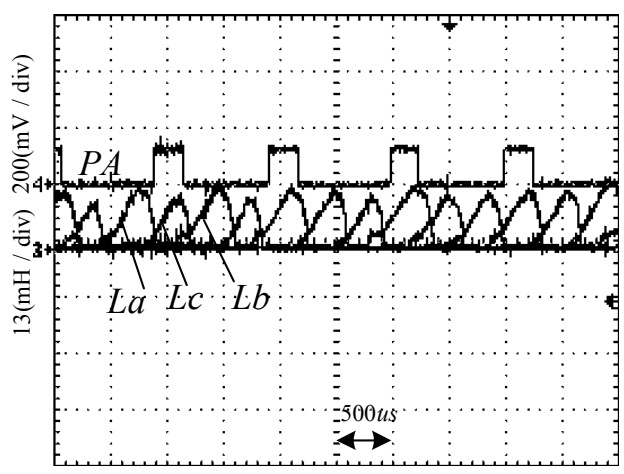

(b) IPISZ with $\theta_{\text {on }}=-3^{\circ}$.

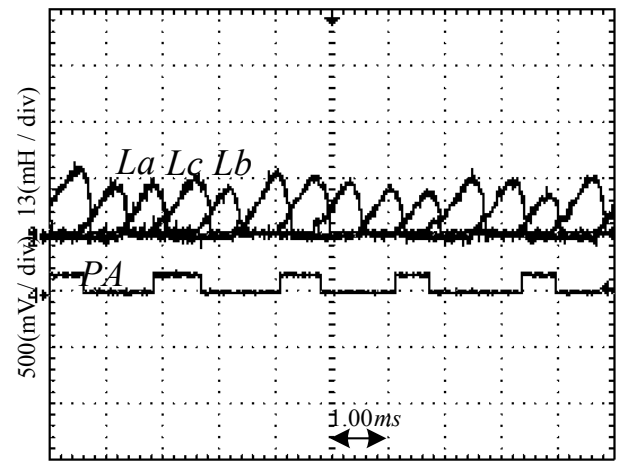

(c) PISZ with $\theta_{\text {on }}=0^{\circ}$.

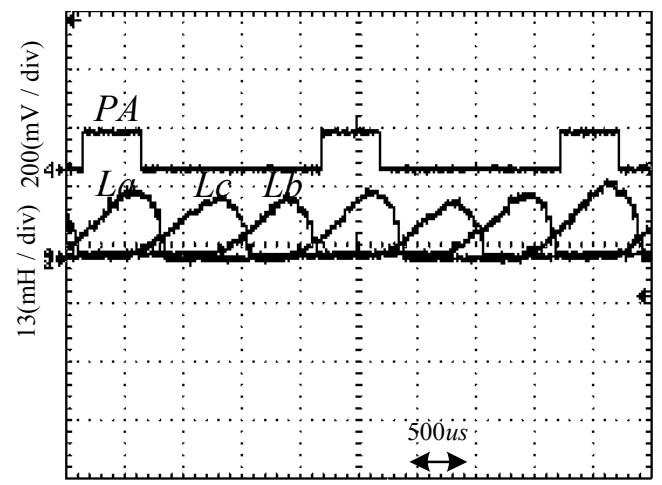

(d) IPISZ with $\theta_{\text {on }}=0^{\circ}$.

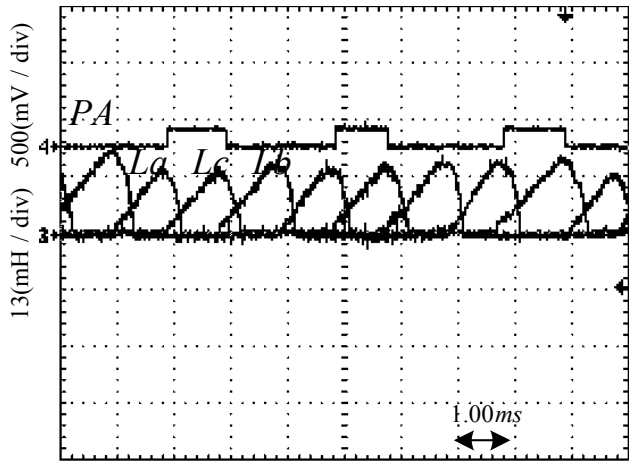

(d) PISZ with $\theta_{\text {on }}=3^{\circ}$

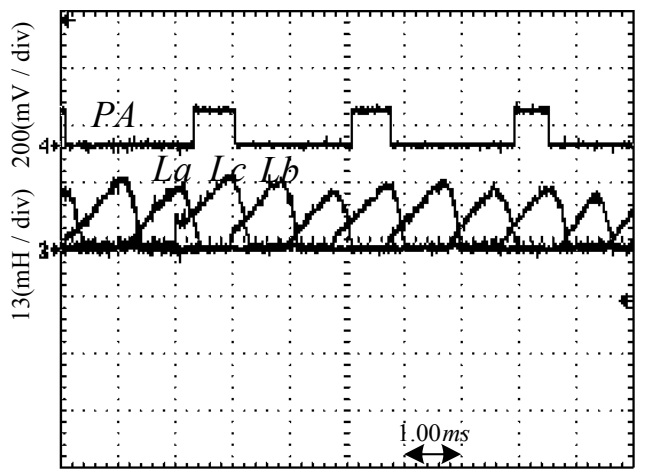

(e) IPISZ with $\theta_{\text {on }}=3^{\circ}$

Fig. 9. Comparison of the estimation results of PISZ and IPISZ with different advanced angle.

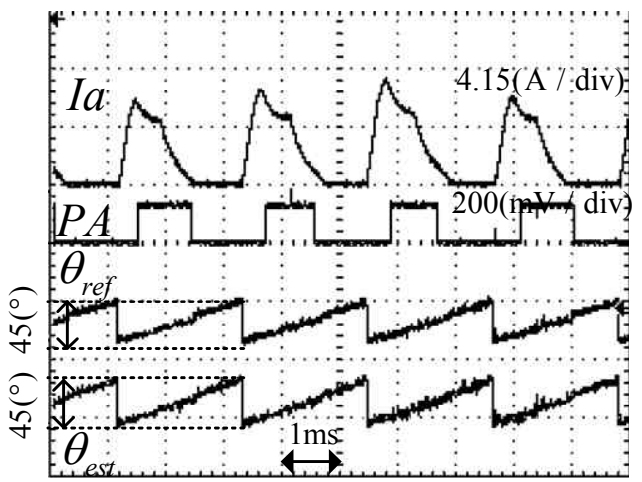

Fig. 10. The position estimation results under IPISZ.

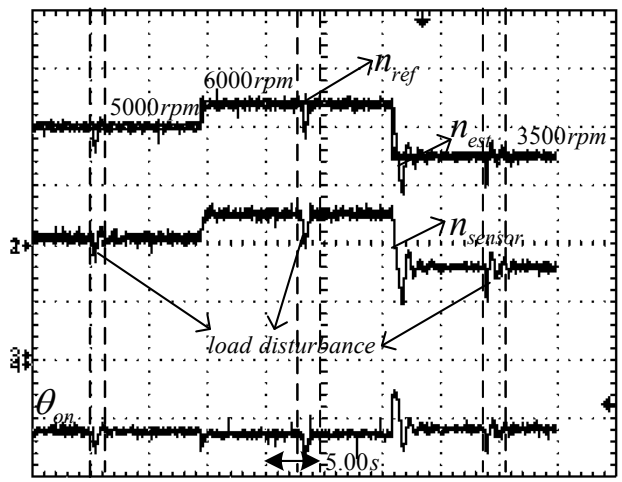

Fig. 11. The sensorless speed transients and the transient response to random load disturbance under normal operation. 


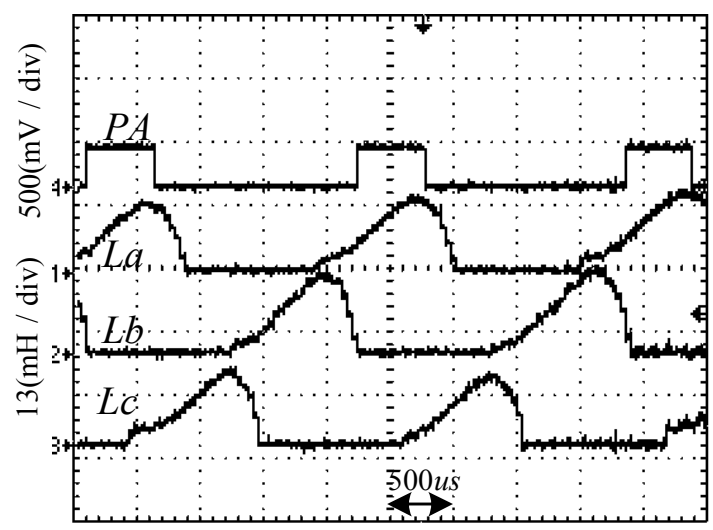

(a) Under normal operation.

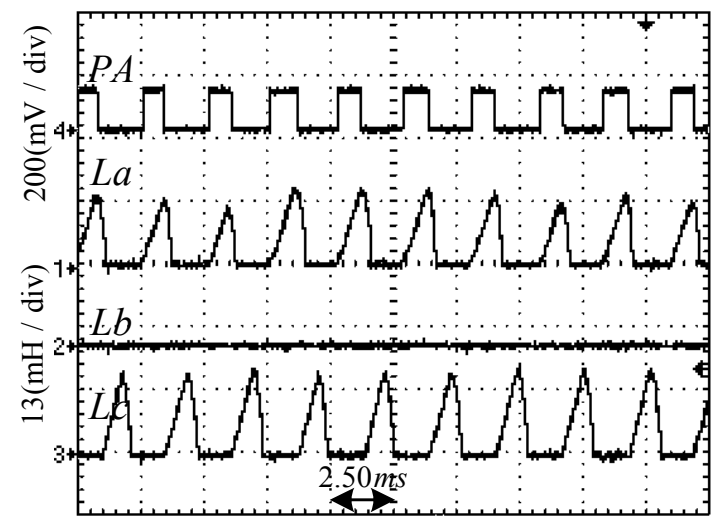

(b) Under one-phase lacking fault.

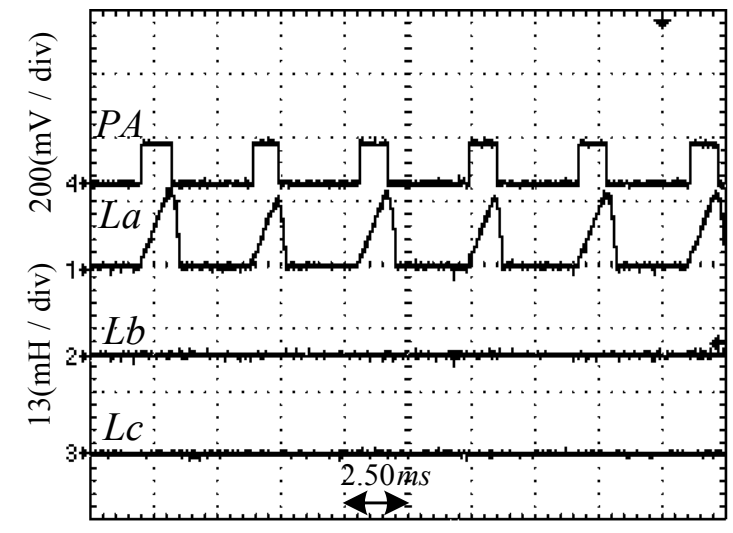

(c) Under two-phase lacking fault.

Fig. 12. Comparison of the sensorless running state under different operation conditions.

In order to verify the dynamic performance, under normal operation mode, the IPISZ method is utilized for sensorless closed-loop control. The speed transient performance of the sensorless method is shown in Fig. 11. As shown in this figure, the sensorless scheme works well at a series of speed transients both in acceleration and deceleration. Clearly, the sensorless control performance is comparable with those of position sensors control mode. In addition, the sensorless drive's response to steps of random load disturbance at 5000 rpm, $6000 \mathrm{rpm}$ and $3500 \mathrm{rpm}$ are shown in Fig. 11. As can be

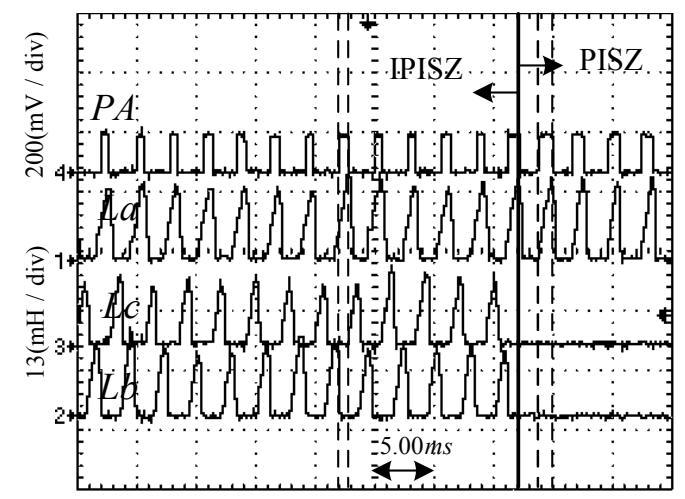

(d)

Fig. 13. The dynamic transient performance from normal operation and fault-tolerant operation.

seen in this figure, the turn-on angle $\theta_{\text {on }}$ can be adjusted automatically for generating suitable torque to overcome the load fluctuation. These experimental results indicate that the sensorless drive system possesses good speed adjusting performance and capacity of resisting load disturbance.

However, in this method, the estimated rotor position depends on the estimated three-phase inductance at any instants; thus, the sensorless method will fail under fault conditions. In contrary, in the PISZ method, the turn-on angle can not be advanced, but the rotor position can be estimated from any individual phases; hence, this method possesses good fault-tolerant capability under phase lacking faults.

The position estimation results under normal operation, one-phase lacking fault and two-phase lacking fault, are shown in Figs. 12(a)-(c) respectively. As shown in Fig. 12(a), the position index pulses are estimated by the IPISZ method, and the system is working in closed-loop control mode with the reference speed at $3500 \mathrm{rpm}$. When the B-phase is lacking, the control system is switching to the fault-tolerant control mode. As shown in Fig. 12(b), the rotor position is estimated by the PISZ method, and the system is controlled under open-loop mode with $\theta_{o n}=2^{\circ}$ and $\theta_{\text {off }}=17^{\circ}$. Keeping other control conditions, the rotor speed is reduced to $2600 \mathrm{rpm}$. Similarly, as shown in Fig. 12(c), B and C phases are lacking at the same time, while the rotor position can still be estimated by PISZ method. The dynamic transients of the rotor position estimation between normal operation and fault-tolerant operation are shown in Fig. 13. As shown in this figure, when the two-phase lacking fault occurs, the position estimation scheme is switched from IPISZ to PISZ automatically and swiftly, and the position index pulses can still be detected without any distortion.

Based on the control logics as shown in Table 3 and 4, the sensorless starting scheme is also implemented in our system. As shown in Fig. 14, combining the control logics at standstill and low speed operation, the SRM can be started from standstill reliably without any hesitation. Fig. 15 shows the three-phase current under low speed operation, as 


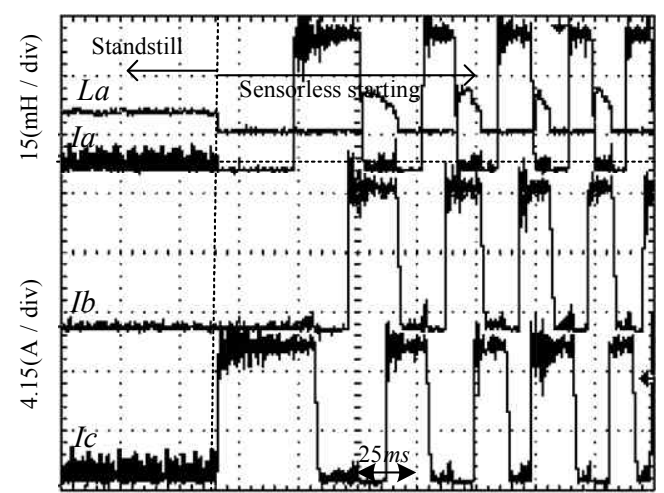

Fig. 14. The sensorless starting process.

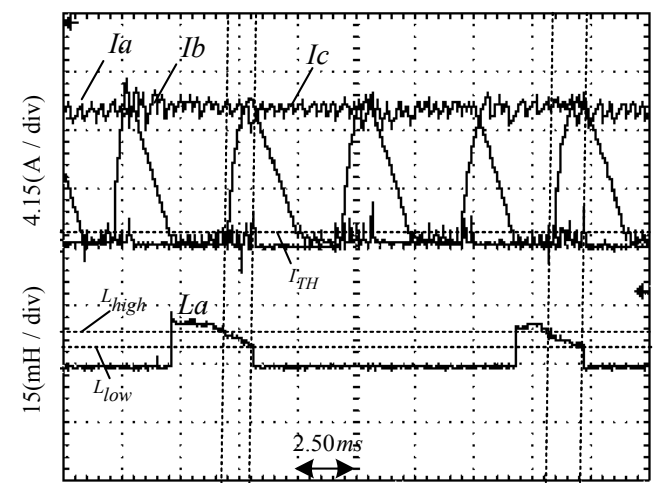

Fig. 15. The sensorless operation under low speed.

compared with Fig. 6; the experiments are in good agreement with the basic principle, which fully verified the validity of the proposed sensorless starting scheme.

\section{CONCLUSIONS}

The PISZ based sensorless rotor position estimation method is investigated systematically in this paper. The theoretical analysis shows that this method is not suitable for the case with turn-on angle advanced. To solve this problem, a simple phase inductance subregion method is developed for improving the PISZ. The PISZ and IPISZ methods are compared through theoretical analysis. The results show that the IPISZ method is not affected by the changes of advanced angle, but it is not able to maintain fault-tolerant sensorless operation under phase lacking faults. The PISZ possesses good fault-tolerant capability, but the turn-on angle can not be advanced. The influence factors of the sensorless schemes are also analyzed systematically in this paper. Due to the inaccuracy estimation of flux linkage at low speed region, the proposed sensorless position estimation method is not suitable for low speed operation. To solve this problem, an idle phase inductance thresholds based sensorless starting scheme is also proposed. Finally, experimental results fully verified the proposed sensorless scheme. The experiments show that the proposed methods are quite easy for implementation without additional hardware, complex calculation and huge memory, which possesses good generality, practicality, and reliability, and is suitable for use in many cost-effective industrial applications.

\section{ACKNOWLEDGEMENT}

This work is supported in part by The National Natural Science Foundation of China (51277094).

\section{REFERENCES}

[1] M. Ehsani and B. Fahimi, "Elimination of position sensors in switched reluctance motor drives: state of the art and future trends," IEEE Trans. Ind. Eletron. Vol. 49, No. 1, pp. 40-47, Feb. 2002.

[2] F. R. Salmasi, "Sensorless control of the switched reluctance motor drive based on back EMF estimation," Ph.D. dissertation, Texas A\&M University USA, 2002.

[3] I. H. Al-Bahadly, "Examination of a sensorless rotor-position-measurement method for switched reluctance drive," IEEE Trans Ind. Eletron. Vol. 55, No. 1, pp. 288-295, Jan. 2008.

[4] H. Gao, F. R. Salmasi, and M. Ehsani, "Inductance model-based sensorless control of the switched reluctance motor drive at low speed," IEEE Trans. Power Electron., Vol. 19, No. 6, pp. 1568-1573, Nov. 2004.

[5] B. Fahimi, A. Emadi, B. S. J. Raymond, "Four-quadrant position sensorless control in SRM drives over the entire speed range," IEEE Trans. Power Electron., Vol. 20, No. 1, pp. 154-163, Jan. 2005.

[6] S. A. Hossain, I. Husain, H. Klode, B. Lequensne, and A. M Omekanda, "Four quadrant and zero speed sensorless control of a switched reluctance motor," IEEE Trans. Ind. Applicat., Vol. 39, No. 5, pp. 1343-1349, Sep./Oct. 2003.

[7] A. Khalil, S. Underwood, I. Husain, H. Klode, B. Lequensne, S. Gopalakrishnan, and A. M. Omekanda, "Four quadrant pulse injection and sliding-mode-observer-based sensorless operation of a switched reluctance machine over entire speed range including zero speed," IEEE Trans. Ind. Appl., Vol. 43, No. 3, pp. 714-723, May/Jun. 2007.

[8] L. Xu and C. Wang, "Accurate rotor position detection and sensorless control of SRM for super-high speed operation," IEEE Trans. Power Electron., Vol. 17, No. 5, pp. 757-763, Sept. 2002.

[9] S. Paramasivam, S. Vijayan, M. Vasudevan, R. Arumugam, and R. Krishnan, "Real-Time Verification of AI Based Rotor Position Estimation Techniques for a 6/4 Pole Switched Reluctance Motor Drive," IEEE Trans. Magn., Vol. 43, No. 7, pp. 3209-3222, Jul. 2007.

[10] C. A. Hudson, N. S. Lobo, and R. Krishnan, "Sensorless control of single switch-based switched reluctance motor drive using neural network," IEEE Trans. Ind. Eletron., Vol. 55, No. 1, pp. 321-329, Jan. 2008

[11] E. Echenique, J. Dixon, R. Cardenas, R. Pena. "Sensorless control of a switched reluctance wind generator, based on current slopes and neural networks," IEEE Trans. Ind. Eletron. Vol. 56, No. 3, pp. 817-825, Feb. 2009.

[12] G. Lopez, P. C. Kjaer, and T. J. E. Miller, "A new sensorless method for switched reluctance motor dirves," IEEE Trans. Ind. Applicat., Vol. 34, No. 4, pp. 832-840, Jul./Aug. 1998.

[13] C. J. Bateman, B. C. Mecrow, A. C. Clothier, P. P. Acarnley, and N. D. Tuftnell. "Sensorless operation of an 
ultral-high-speed switched reluctance machine," IEEE Trans. Ind. Applicat., Vol. 46, No. 6, pp. 2329-2337, Nov./Dec. 2010.

[14] I. Miki, H. Noda and R. Moriyama, "A sensorless drive method for switched reluctance motor based on gradient of phase inductance," ICEMS 2003, Vol. 2, pp. 615-618, Nov. 2003.

[15] H. H. Moghbelli, G. E. Adams and R. G. Hoft, "Prediction of the instantaneous and steady state torque of the switched reluctance motor using finite element method (FEM)," IEEE-IAS Annu. Meeting, pp. 59-70, 1988.

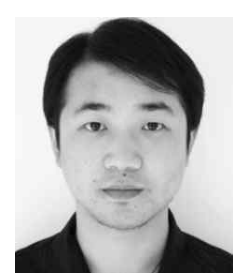

Jun Cai was born in Hunan Province, China, in 1982. He received the B.S. degree in electrical engineering in 2005 from Beijing institute of petrochemical technology, Beijing, China, and he received the Ph.D. degree in electrical engineering in 2012 from Nanjing University of Aeronautics and Astronautics, Nanjing, China. $\mathrm{He}$ is an author of more than 30 peer reviewed journal and conference papers, and holds 14 patents. His current research interests include switched reluctance starter/generator, linear motor, motor drive system for $\mathrm{EV}$, sensorless techniques, and smart grid technology.

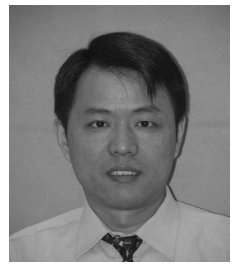

Zhiquan Deng was born in Hubei Province, China, in 1969. He received the B.S. degree in mechanical engineering from Xian Institute of Metallurgy and Construction Engineering (Renamed as Xian University of Architecture \& Technology since 1994), Xian, China, in 1990, and M.S., Ph.D. degrees in Engineering Machinery from Northeastern University, Shenyang, China, in 1993 and 1996, respectively. In 1996, he was a Post-Doctoral at Nanjing University of Aeronautics \& Astronautics, Nanjing, China. In 1998, he joined the Department of Electrical Engineering, Nanjing University of Aeronautics \& Astronautics, Nanjing, China, where he is currently a Professor in the College of Automatic Engineering. He is engaged in research on bearingless motor drive systems, magnetic bearings, super high speed electrical machines. 